\title{
SKILLS AND ABILITIES ALIGNED WITH THE CURRENT MARKET CONTEXT
}

\author{
María Dolores Andújar-Montoya, Encarnación García-González, \\ M. Asunción López-Peral
}

Universidad de Alicante (SPAIN)

\begin{abstract}
The European Commission -through the Communication Rethinking Education: investing in skills for better socio-economic outcomes- establishes in 2012 the new guidelines of education systems aligned with current labour markets, i.e. patterns for adaptation of qualifications in line with the new demands of the 21st century. One of the main lines of action proposed in the reform focuses on the development of skills as a strategic asset for growth. Within the framework of skills development, vocational skills are considered as a fundamental pillar that allows the development of skills, both basic and transverse, to shorten distances between universities and companies, i.e., they allow bringing high education students closer to the reality of working environments. Likewise, it is considered the development of entrepreneurial skills among the students. This fact contributes not only to the future creation of new organisations, but also to the employability of young people. Parallel to this new paradigm of academic restructuring, the students of the Architectural Technologist Degree face the Final Grade Work at their final academic stage. However, paradoxically instead of facing this last phase of the degree with concern for learning, entrepreneurship, ambition and satisfaction for what has been achieved up to that time, a high percentage of these students show individualism, demotivation, insecurity and fear of the development of Final Grade Work. As a consequence, the main objective of this research is focused on how can be promoted the development of vocational skills and entrepreneurial skills in these students who approach the work environment through the completion of Final Grade Work. Therefore, the present work is based on the identification and analysis of causes that encourage such demotivation, individualism, insecurity and fear in the subject of Final Grade Work through a case study. Specifically, the case study focuses on a group of students with same opportunities and similar characteristics, that is, with the same thematic area of Final Grade Work, the same tutor and identical deadlines. From the results obtained in the above analysis, it is presented a solution based on coaching strategies. Coaching is a tool whose success has been widely validated in other fields such as business or sports, which acts as a motor of change allowing the optimal performance and improvement of professional results - both individual and group - through techniques of analysis and motivation. In order to carry out the experimentation, we had the support of a professional coach of great experience and with training in the program of Success Unlimited Network. Through coaching sessions as a motivational tool, it was possible to integrate the Being/Doing of each participant - including not only students but also teachers - in an individual way to improve the attitude of the students to challenge the Final Grade Work, and therefore, to achieve the monthly goals set in each meeting. In addition, Team Building sessions were included in order to reinforce the collaboration among the participants, thus improving the team's overall performance, bringing them closer to the new cooperative and collaborative work methodologies that mark the current market conditions.
\end{abstract}

Keywords: vocational skills, entrepreneurial skills, coach, collaborative work, team building.

\section{INTRODUCTION}

The current market in general, and more specifically the construction sector, is immersed in a process of reinvention. The current social and economic-financial context -characterized by higher expectations of customer, global competition, technological changes and scarce funding- leads traditional models to failure [1, 2]. As a consequence, a change of mentality is taking place in order to improve quality and productivity of the industry. This change of mind is also translatable to higher education models in order to prepare students for an immediate professional future, under the market characteristics specified above.

Specifically in the Architectural Technologist Degree, the current students will have to deal with greater competition due to the large number of graduates, result of the real estate bubble that made 
an impact in all studies related with the construction sector, i.e. Architects, Architectural Technologist, Civil Engineers, etc.. Also, internalization and the elimination of geographical barriers increase the volume of competition in possible job offers. Given this competitive environment, students must fit on it through the development of skills according to the new business demands. This means that companies in general, especially those that include departments of HR, not only will they value students by the knowledge acquired during their university studies, but also they will assess other transversal skills and attitudes related to interpersonal relationships and teamwork, autonomy and personal development and values [3,4]. These skills and attitudes include communication abilities, teamwork and collaboration, ability to work in international contexts, resolution capability, entrepreneurship and leadership, networking, teamwork and collaboration, commitment and their identification with the corporate identity.

At the same time, the students of the information and digital age are immersed in the technological paradigm shift, with a wide variety of useful software. Especially now that the BIM methodology -and all its varied range of associated tools - is running as the engine of change in the construction sector. The wide variety of software makes it impossible to have them fully integrated into university curricula. In this context, while university lecturers guide students in the subject contents and specific software, other aspects such as self-learning through webinars, tutorials, MOOCs, ted-talks, among others, are starting to be indispensable.

In this background of change, the European Commission -through the Communication Rethinking Education: investing in skills for better socio-economic outcomes- establishes in 2012 the new guidelines of education systems aligned with current labour markets, i.e. patterns for adaptation of qualifications in line with the new demands of the 21st century. One of the main lines of action proposed in the reform focuses on the future creation of new organisations and the employability of young people through the development of skills as a strategic asset for growth. Within the framework of personal development and skills development, vocational skills are considered as a fundamental pillar that allows the development of skills, both basic and transverse, to shorten distances between universities and companies, i.e., they allow bringing high education students closer to the reality of working environments.

Parallel to this new paradigm of academic restructuring, the students of the Architectural Technologist Degree face the Final Grade Work at their final academic stage. However, paradoxically instead of facing this last phase of the degree with concern for learning, entrepreneurship, ambition and satisfaction for what has been achieved up to that time, a high percentage of these students show individualism, demotivation, insecurity and fear of the development of Final Grade Work. As a consequence, the main objective of this research is focused on how can be promoted the development of vocational skills and entrepreneurial skills in these students who approach the work environment through the completion of Final Grade Work.

\section{METHODOLOGY}

Following specified above, the present work is based on the identification and analysis of causes that encourage such demotivation, individualism, insecurity and fear in the subject of Final Grade Work through a case study. From the results obtained in the above analysis, it is presented a solution based on coaching strategies.

Coaching is a tool whose success has been widely validated in other fields such as business or sports, which acts as a motor of change allowing the optimal performance and improvement of professional results - both individual and group - through techniques of analysis and motivation. In order to carry out the experimentation, we had the support of a professional coach of great experience and with training in the program of Success Unlimited Network that ran the coaching sessions as an individual motivational tool. In addition, Team Building sessions were included in order to reinforce the collaboration among the participants (Fig.1). 


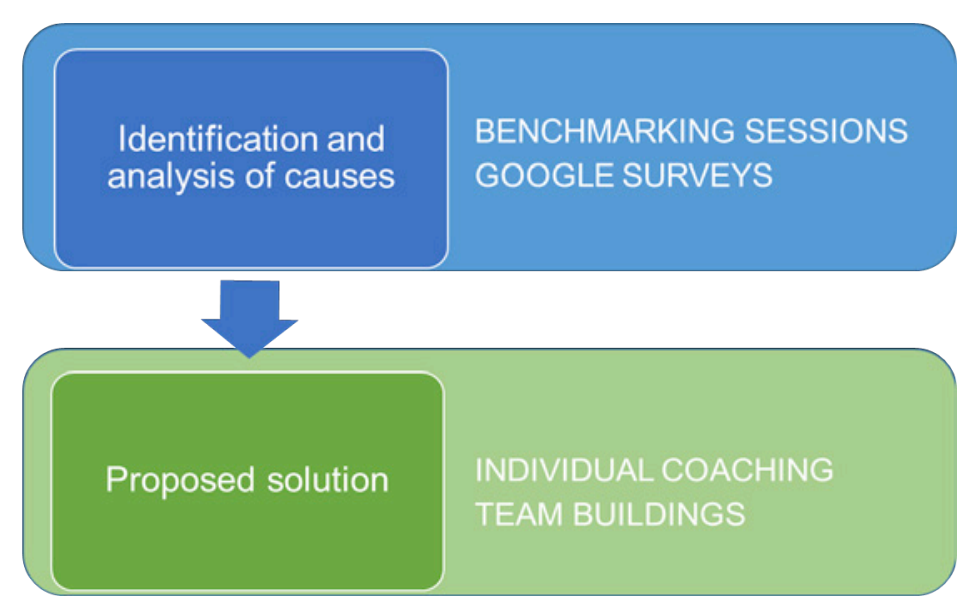

Figure 1. Methodology used in each stage of the study case.

\section{CASE STUDY: FINAL GRADE WORK TEAM}

\subsection{Stage 1: Identification and analysis of causes}

The present research has been carried out through a case study within the framework of the Final Grade Work of Architectural Technologist Degree. Specifically, the case study focuses on a group of students with same opportunities and similar characteristics, that is, with the same thematic area of Final Grade Work, the same tutor and identical deadlines.

The first stage of the research included the identification and analysis of barriers faced by students during their Final Grade Work. To do this, two related initiatives were carried out. First, google surveys were conducted to all project participants, both students and teachers. Secondly, these surveys were analysed through benchmarking sessions to identify the root of the problem (Fig.2).
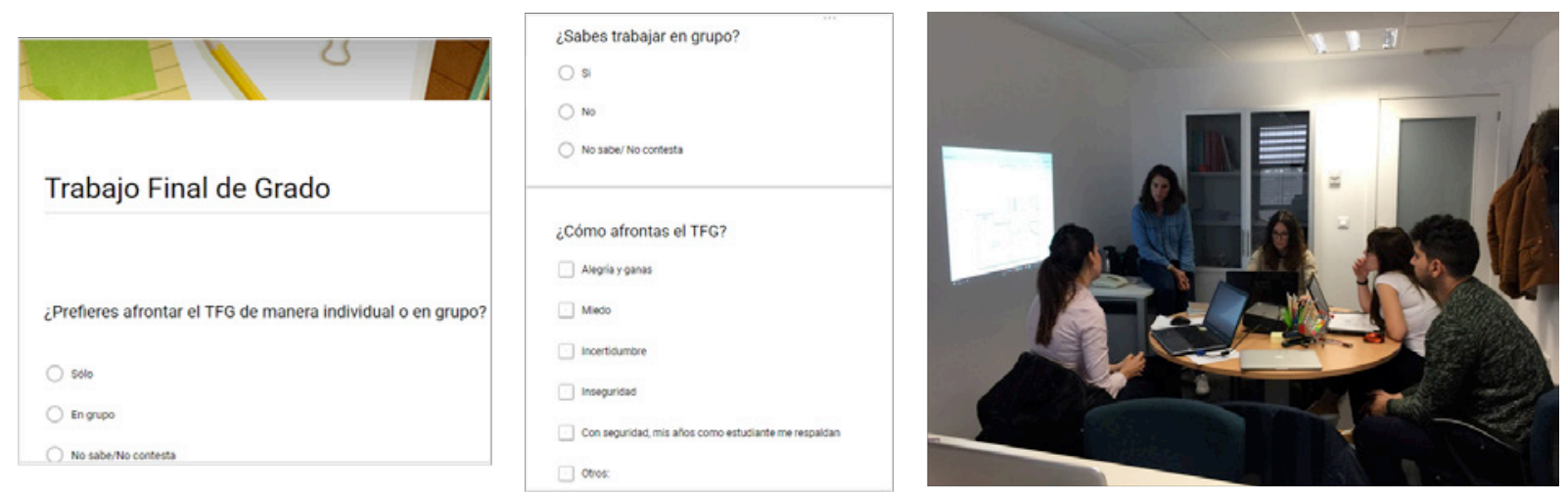

Figure 2. Initiatives carried out in the case study (a) extract of google survey

(b) Benchmarking session number 1.

In total 5 students participated answering the google surveys, in addition to participating in the benchmarking sessions. In addition, 3 teachers participated in the benchmarking sessions and an external coach was introduced in the second stage of research.

After carrying out both initiatives, it was deduced the next:

- Most of them like the idea of cooperation, but they realise that they do not know how to collaborate and work in multidisciplinary work teams ( $80 \%$ of participants). Some of them state that they feel that have not practise work teams during previous years of the degree.

- None of the participants feel facing their last period in the university with motivation and joy. Instead, they feel demotivation, insecurity and fear (100\% of participants).

- Most of them feel far from the reality of working environments ( $80 \%$ of participants). 
- Part of them ( $60 \%$ of participants) does not develop vocational skills because they do not know them, since they do not self-analyse, and therefore, they do not know which part of themselves they should improve and work.

- All of them (100\% of participants) affirm that they do not know how to work within international contexts.

- A high percentage does not know what co-working and networking means.

- They are tired of studying but at the same time are afraid of future employment.

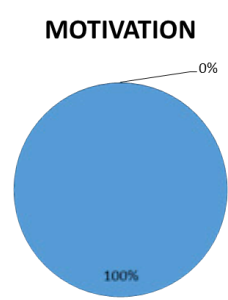

COOPERATION

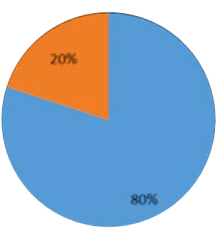

WORKING ENVIRONMENTS

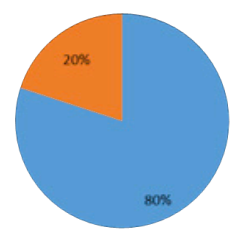

SKILLS

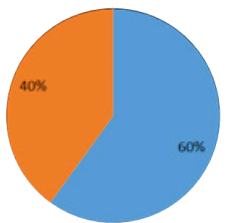

INTERNALIZATION

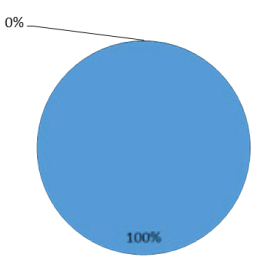

CO-WORKING AND NETWORKING

Figure 3. Extract of google survey results.

\subsection{Stage 2: Proposed solution}

As shown in the previous section, a high percentage of students show individualism, demotivation, insecurity and fear of the development of Final Grade Work instead of facing this last phase of the degree with concern for learning, entrepreneurship, ambition and satisfaction for what has been achieved up to that time. The second stage of the present research is focused on how can be promoted the development of vocational skills and entrepreneurial skills in these students who approach the work environment through the completion of Final Grade Work. Therefore, the proposed solution is based on coaching strategies. Coaching is a tool whose success has been widely validated in other fields such as business or sports, which acts as a motor of change allowing the optimal performance and improvement of professional results - both individual and group - through techniques of analysis and motivation. In order to carry out the experimentation, we had the support of a professional coach of great experience and with training in the program of Success Unlimited Network.

The concept of modern Coaching was created in 1992, by American Thomas Leonard, who cofounded Coach University (CoachU) in 1992 and in 1994 the International Coach Federation (ICF) and the International Association of Coaches (IAC), being the latter the largest professional coaching association in the world. Coaching is a technique of development or personal growth that through exercises achieves -among other things- people to face their fears, loneliness, heaviness, frustrations, etc... Likewise the aim of coaching is to transform those feelings into confidence both in themselves and in others. The technique is applicable to all different aspects of people, covering the professional aspects, personal economy, family life, relationships, health, spirit and personal relationships.

In the context of higher education studies, coaching is postulated as a methodological technique that promotes the development of human potential, helping students to evolve, from where they are today to where they intend to reach tomorrow. This methodology is based on the establishment of personal goals and the execution of a series of planned actions to achieve them [5]. Furthermore, it facilitates the empowerment of our own resources [6].

To develop the case study we had the support of a professional coach of great experience, who helped us to establish a process that first deals with the search of participants' personal identity, and secondly to look for their professional identity. To develop it, we worked on the following nine tools:

- Self-knowledge: Both personal and professional. Where you are and where to go. 
- Understanding your emotions.

- Purpose-sense. Not only of the student/professional but also the team, as a great motivational tool.

- Introspection. Beliefs-values. Student/professional as a person.

- Route map. In the medium term of the student/professional.

- Routines.

- Setting goals. Integrating in short term BE / DO / HAVE.

- Organization. Personal and professional.

- Keys. To achieve daily and weekly goals.

- Live action. Know how to focus on here and now.

During the whole year, the participant coach held individual sessions with the students and teachers that participated in the case study, in order to develop the above coaching tools. In addition, Team Building sessions were included in order to reinforce the collaboration among the participants, thus improving the team's overall performance, bringing them closer to the new cooperative and collaborative work methodologies that mark the current market conditions. Team building sessions are increasingly proliferating in large innovative companies, which are focused on motivating their workers to improve their performance. In addition its benefits have also been highlighted in the scientific literature [7, 8]. In the case study sessions consisted of a mini-league of tennis guided by the coach, expert in the field of sports coach. The change of roles teacher-student and the change of scenery led to greater emotional openness among participants, diluting barriers of adversity and improving cooperativity during the team building activities. As the future of the line of work, it will be developed the specific analysis of the behaviours during the team buildings sessions.

\section{CONCLUSIONS}

After the development of the research stages that focused on both individual and collective improvement, the following conclusions were drawn from each of the actions. Through coaching sessions as a motivational tool, it was possible to integrate the Being/Doing of each participant including not only students but also teachers - in an individual way to improve the attitude of the students to challenge the Final Grade Work, and therefore, to achieve the monthly goals set in each meeting. Likewise, Team Building sessions reinforced the collaboration among the participants, thus improving the team's overall performance, bringing them closer to the new cooperative and collaborative work methodologies that mark the current market conditions.

\section{REFERENCES}

[1] M.D. Andújar-Montoya, "Modelo de gestión integral de la ejecución de la obra para la personalización masiva en edificación residencial. Un enfoque basado en BPM", Universidad de Alicante. 2015

[2] M.D. Andújar-Montoya, et al., "A construction management framework for mass customisation in traditional construction". Sustainability. 7(5): p. 5182-5210. 2015.

[3] V.G. Maura and R. Tirados, "Competencias genéricas y formación profesional: un análisis desde la docencia universitaria”. Revista iberoamericana de educación. 47: p. 185-209. 2008.

[4] S. Bridge and K. O'Neill, "Understanding enterprise: entrepreneurship and small business": Palgrave Macmillan. 2012.

[5] B.S. Mirón and J.B. Mundina, "Educational coaching: a model for the development of intra and interpersonal skills". Educación xx1. 17(1): p. 221. 2014.

[6] J.F.B. Pérez, "Coaching para docentes: el desarrollo de habilidades en el aula". Editorial Club Universitario. 2009.

[7] Millis, B.J. and P.G. Cottell Jr, "Cooperative Learning for Higher Education Faculty". Series on Higher Education. ERIC. 1997. 
[8] E.M Bensimon, "Redesigning collegiate leadership: Teams and teamwork in higher education". Johns Hopkins University Press.1993. 